Psychology of Language and Communication 2021, Vol. 25, No. 1

Sciendo

DOI: $10.2478 /$ plc-2021-0007

\author{
Søren Beck Nielsen \\ Faculty of Humanities, University of Copenhagen, Denmark
}

\title{
Interactional integration of talk and note-taking
}

\begin{abstract}
This paper contributes to the current line of research that examines how participants interactionally engage in simultaneous multiple courses of actions. It looks into how institutional interactants jointly integrate two concurrent engagements: talk and notetaking. It builds upon video recordings of naturally occurring monitoring visits in Denmark, where social supervision representatives interview foster parents and facility leaders and simultaneously take notes on their laptop computers. Data suggest that talk and notetaking concur very commonly, that is, representatives take notes extensively while the other party talks. The paper investigates three factors that advance our knowledge about interactional reasons why this dual engagement can take place so commonly. First, when initiating concurring writing or talk, both parties orient towards simultaneous engagement in the two activities as appropriate. Second, whilst writing, representatives verbally display recipiency to talk, which prompt speakers to continue. Third, representatives frequently suspend the act of writing in order to briefly face the speakers, which they similarly treat as an encouragement to continue.
\end{abstract}

Key words: conversation analysis, multiactivity, institutional interaction

Address for correspondence: Søren Beck Nielsen, University of Copenhagen, University of Copenhagen, Faculty of Humanities, Department of Nordic Studies and Linguistics, Njalsgade 136, $2300 \mathrm{Kbh}$. S

E-mail: sbnielsen@hum.ku.dk

This is an open access article licensed under the CC BY NC ND 4.0 License. 
Research on multitasking in experimental psychology has long and comprehensive history of examining if individuals can engage in more than one motor and/or cognitive task at the time, and how such dual commitments affect their performance (e.g., Duncan, 1979; Meiran, 1996; Pashler, 1984; Rogers \& Monsell, 1995). Some of the recent and very specific, yet fundamental, topics, which this line of research helps elucidate, include: the relationship between age multitasking ability (Wechsler et al. 2018), how well other populations, for example students, multitask (Bowman et al., 2010), or how multitasking performance correlates with predictability (i.e., implicit or explicit knowledge about what to do; Ewolds et al., 2017).

In the last decade, interactional research on multiactivity has offered an alternative to this experimental research (see Haddington, 2019; Haddington et al., 2014). This alternative consists of detailed analyses of naturally occurring video recordings of talk-in-interaction in which participants are engaged in two or more concurrent or serial courses of action. While research on multitasking (sometimes referred to as dual-task) typically adopts a "broader, individual and cognitive perspective on the phenomenon," research on multiactivity highlights the "social, interactional and temporal features of situations and conduct in which people organise multiple activities together" (Haddington et al., 2014, p. 5). Thus, multiactivity studies explain concurrent engagements not, for example, as an outcome of individual or cognitive capacities, but rather as the participants' systematic exploitation of interactional resources.

In reality, the two perspectives, cognition and interactional organisation, are two sides of the same coin as, for instance, theorized by scholars who explore distributed language and cognition (see e.g., Cowley, 2012; Jensen, 2014, 2018; Trasmundi 2020; Trasmundi \& Steffensen, 2016). Without failing to recognize this complex duality, however, students of multiactivity focus almost exclusively on the interactional aspect. This focus not only advances our understanding of social situations, but also offers detailed insights about interactional processes and how actors can manage dual engagements because they methodically attune activities to one another or prioritize among them. For example, drivers may convergently talk about the route or the emerging elements of traffic with passengers while driving (Mondada, 2012). Conversely, actors may attend to a summon by putting a current activity on hold (e.g., Licoppe \& Tuncer, 2014). It is, however, often more rewarding to regard dual engagements as distributed along continuums as opposed to either/or choices (Mondada, 2014).

Terminological transparency is crucial - without clear criteria, almost everything individuals do during waking hours could be construed as exhibiting multiple engagements. On the basis of actors' participation in interaction, Lorenza Mondada (2012, p. 226) defined multiactivity as "multiple simultaneous courses of action that can be variously related, have a specific sequential organization, and be coordinated." Two things in particular are worth noting from this definition. First, "courses of action" implies that multiactivity typically refers to strings of 
coherent actions rather two concurrent or subsequent singular actions. Second, Mondada's use of modality emphasizes that courses of action can be related, organized, and coordinated to constitute multiactivity, but need not be. In other words, it depends upon whether or not participants themselves orient towards the courses of action as interrelated. Some multiactivity studies focus upon ways of administering two concurrent verbal interactions, for example, making phone calls during face-to-face interactions (Ticca, 2014). But, by far, most multiactivity studies elucidate how actors administer conversational participation in conjunction with some other embodied activity (that may include the use of material objects, tools, and technological devices), for instance, walking and talking (Mondada, 2017), conversing while doing manual labour (Keevallik, 2018), massaging and conversing (Nishizaka \& Sunaga, 2015), eating and talking (Mondada, 2009), drinking coffee and closing down a conversation (Laurier, 2008), and talking while listening to music (Heinemann \& Rauniomaa, 2016).

A series of studies have examined actors' dual commitment in verbal and textual courses of action. Some looked closely into situations where interactants read something while conversing (e.g., Beck Nielsen, 2016; Halldorsdottir, 2006; Ruusuvuori, 2001; Svinhufvud \& Vehviläinen, 2013). Other studies focused more upon writing as an integral feature of talk (see Mondada \& Svinhufvud, 2016). In particular, many studies examined how writing practices, with writers using different media (e.g., handwritten notes on paper, computer typing, voice dictation, etc.), are pivotal to institutional interaction and constitute goal-oriented action, for example, in judicial settings (González Martínez, 2006; Komter, 2006, 2012), educational situations (Hazel \& Mortensen, 2014; Svinhufvud, 2016), political scenes (Mondada, 2016), business meetings (Streeck \& Kallmeyer, 2001), medical contexts (Beck Nielsen, 2014; Greatbatch 2006), or related to social work (Monteiro, 2016).

The present study contributes to this line of inquiry with an examination of the integration of talk and writing in connection with a particular kind of social work in Denmark: monitoring visits. Monitoring visits are organized by social supervision centers. The main purpose of these centers is to ensure that citizens, in particular foster children and facility residents, are provided good social service in accordance with standards and legal regulations. The centers employ a large number of representatives to supervise and assess the work of foster parents and facilities for adolescents or impaired adults. Monitoring visits are meetings held between social supervision representatives and foster parents or leaders of facilities for adolescents or impaired adults. They take place in foster parents' homes or at the facilities for adolescents or impaired adults. During the meetings, participants cover a wide range of topics that help representatives supervise foster parents and facility leaders and assess their work. Much of this talk is question-answer driven, similar to an interview, that is, representatives inquire about various matters (e.g., regarding initiatives to ensure the well-being of foster children or residents), which foster parents or facility leaders respond 
to. Representatives bring laptop computers for the meetings and use them quite extensively during the visits to take notes (see Table 1). Later, they incorporate the notes in a report draft, which they submit to hearing to the foster parents or facility leaders in question. Following this hearing, representatives complete and publish their reports, which entail an important assessment, since the social supervision center has the authority to renew or reject the license of foster parents and facilities alike.

The actual writing is manifested as computer typing. Typically, representatives do not share what they write on their computers. But the fact that they write is observable (i.e., visible and audible) to co-participants (see also Komter, 2006). Thus, the current study's research question was: how are the two courses of actions (i.e., talk and writing) integrated? Previous research on computer typing during institutional face-to-face interaction has offered some accounts. For example, Greatbatch (2006) showed that when general practitioners type prescriptions, patients may observe the typing and await completion before talking. Postponement of talk, then, represents one way of integrating talk-ininteraction and computer typing in institutional interaction. But whereas doctors fill out prescription forms briefly and at quite projectable points in time during consultations, representatives use their computers extensively throughout the lengthy monitoring visits. This difference might call for other kinds of interactional cooperation to administer dual attention, that is, show each other that both courses of action are possible to attend to at the same time. To examine if this is the case, the present study examined three scenarios: (a) how writing sequences are initiated in concurrence with talk-in-interaction, (b) how representatives display listening while they take notes and, thus, possibly encourage continuation of talk; and (c) how representatives display listening between note-taking by very briefly suspending the act of writing in favour of visual engagement with the other participant.

\section{Data and Method}

The current study was conducted in collaboration with one social supervision center in Denmark. Five visits, which took place in a rural district, were video recorded by the author with the written consent of all participants. First, the study was agreed upon by the representatives. Second, the representatives informed the foster parents and the facility leaders and asked beforehand for their permission to have the meeting recorded. Third, on the actual day of the meeting, all participants were asked for permission to video record the meeting. Everyone consented. After the meeting, all participants were offered to have the recording deleted, which everyone declined. In one of five monitoring visits, the representative experienced computer problems and therefore opted to take handwritten notes. This recording was discarded from the current study because it proved difficult to determine 
when exactly writing sequences were initiated and terminated.

Thus, four recordings were examined. All four representatives were female. Two of the recordings (i.e., Recordings 1 and 3 in Table 1) represented monitoring visits at two different facilities: Recording 1 took place at a residence for vulnerable adolescents; Recording 3 took place at a facility for impaired adults. The two remaining recordings represented monitoring visits in private homes of two different foster parents. In Recording 2, both foster parents were present throughout the monitoring visit; in Recording 4, the foster father joined the foster mother and the representative approximately half an hour into to meeting.

The recordings were conducted using a single stationary camera that provided no access to what the representatives wrote on their computers. This limited the amount of data gathered (which could have allowed for examining the possible correlation between representatives' conversational contributions, bodily actions, and what they currently write). On the other hand, since the representatives clearly chose to place their computers on a table between themselves and their co-participants and never turn their computers to invite foster parents or facility leaders to read along, this research design emically afforded the same kind of access that foster parents and facility leaders are given, and thereby allowed for examining their responsive actions without a priori assumptions.

Similar to studies on multiactivity, the current study study used the conversation analytic method to examine the participants' jointly coordinated verbal and bodily actions, the ways in which they exploit conversational structures (e.g., turn-taking systematics), and the intersubjective understandings that they convey through their contributions to the interaction (see e.g., Clift, 2016; Sidnell, 2010). Among other things, this required detailed transcripts that captured not only what the participants said and did, but also when and how they did it (see the Appendix for an index of notation symbols, or Jefferson, 2004, for a detailed account). English translations are placed in italics below the original Danish transcriptions. Furthermore, the sound of computer typing is notated as $*+++*$ aligned with concurrent talk (or silence).

\section{Results}

\section{Initiating Talk and Typing as Concurrent Courses of Actions}

Table 1 provides an overview of the writing activity in the four recordings. It shows how many times representatives engaged in writing sequences defined as lasting simply from the moment they begin to write to the moment they halt, regardless of the length of the pause.

Thus, the representatives spent an average $17 \%$ of the time taking notes on their computers, which regularly concurred with the foster parents' and facility leaders' talk. The following analyses detail how the participants, through their 


\begin{tabular}{|c|c|c|c|c|c|}
\hline & $\begin{array}{c}\text { Duration in } \\
\text { minutes }\end{array}$ & $\begin{array}{c}\text { Number } \\
\text { of writing } \\
\text { sequences }\end{array}$ & $\begin{array}{c}\text { Average duration } \\
\text { of writing } \\
\text { sequence in } \\
\text { seconds }\end{array}$ & $\begin{array}{c}\text { Time spent } \\
\text { writing in } \\
\text { minutes }\end{array}$ & $\begin{array}{l}\text { Percentage } \\
\text { of time spent } \\
\text { writing }\end{array}$ \\
\hline Recording 1 & 89.10 & 65 & 13.4 & 14.58 & $16 \%$ \\
\hline Recording 2 & 119.53 & 149 & 8.1 & 20.23 & $17 \%$ \\
\hline Recording 3 & 66.05 & 184 & 5.1 & 16 & $24 \%$ \\
\hline Recording 4 & 107.18 & 41 & 15.3 & 10.51 & $10 \%$ \\
\hline Total & 381.86 & 439 & --- & 61.32 & -- \\
\hline Averages & 95.5 & 110 & 10.5 & 15.3 & $17 \%$ \\
\hline
\end{tabular}

actions and orientations, show one another that concurrent talk-in-interaction participation and note-taking are not considered mutually exclusive commitments. This orientation manifests itself clearly in two ways that both relate to the fact that monitoring visits predominately unfold as question-answer driven interactions.

First, instead of awaiting possible completion, the representatives begin to take notes while facility leaders or foster parents answer their questions. Put more technically, the representatives commence writing sequences in coincidence with either the onset or a midturn position of the foster parents' or facility leaders' turns-at-talk. An even stronger orientation towards the feasibility of listening and typing at the same time, and also towards note-taking as an expected event occasioned by the forthcoming answer to a current question in progress, may be observed when the representatives prepare to commence writing while they pose the question, for example, by gazing at the computer screen, placing their hands upon the keyboard, or even pressing keys in preparation. Such cases are stronger orientations because the representatives show the foster parents and facility leaders up front that a possible writing is in progress. In Excerpt 1, a representative (REP) asks a foster mother (FOM) how the foster parents handle the practical and emotionally difficult cooperation with the child's biological parents. It is worth noting that as REP initiates this question, she has both of her hands folded in front of her, that is, she is placed in a firm listening position that indicates no sign of transition of attention towards the computer (cf. Schegloff, 1998). This changes, however, merely a few seconds later in Line 02 :

(1). Rec. 2: 23:36-23:44

01. REP: Jeg tænker hvor er I henne (.) i det nu,\#

I'm thinking where are you (.) in this now,

\section{(.2)}

02. REP: i *forældresam*arbejdet, *

in the parent cooperation,

$\star+/+1+1+*$

* REP gazes at computer screen; places right hand on keyboard 
03. FOM: $\varnothing^{*}:$ :hm *altså nu er \#vi jo i v- v- øh nu er samværet jo* Erhm well now we are in $v^{-} v^{-}$erh now the contact takes place

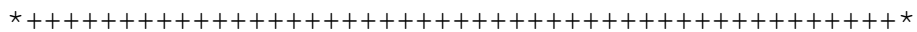

\#Pic. 2

04 . it on keyboard

*i familie*huset, *

in the family house,

$\star++++++\star$

*REP faces FOM; maintains hands on keyboard

*REP gazes at computer

It is also worth noting that REP uses a WH-question format that is likely to solicit an elaborate answer, which FOP's initial clausal response also orients

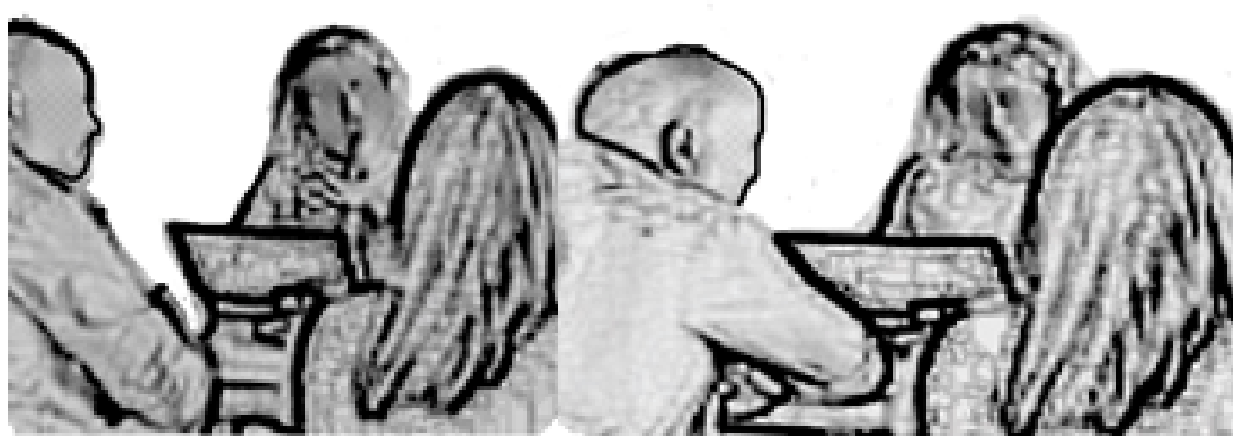

towards (see Fox \& Thompson, 2010), as does her subsequent lengthy account (not in transcript). In the light of an expectable imminent multi-unit turnat-talk from FOM, it is interesting to observe that REP adds an incremental prepositional phrase to her question in Line 02 whilst bodily preparing a fullscale writing sequence by gazing at the computer screen, placing her right hand on the keyboard, and pressing a key a couple of times. In other words, verbally and bodily, REP enacts a transition between, on the one hand, a situation in which she engages solely with the foster parents and, on the other hand, a reconfigured situation in which she concurrently listens and writes. In Line 03, REP effects this reconfiguration when she invokes her left hand as well and types consistently. She types although FOP is nowhere near having answered the question exhaustively, thus, demonstrably enacting that it is not a matter of listening first and writing later, but rather of doing both in unison. In Line 04, however, she does briefly suspend the writing to face the foster mother and, thus, bodily displays listening. This practice will be examined in greater detail below.

Second, foster parents and facility leaders also commonly treat unsolicited talk, while representatives are occupied taking notes, as relevant to produce. This is manifested when they, on their own initiative, take the floor in situations where 
representatives begin to write in silence. Sequentially, this scenario may occur when a representative begins to write upon the completed answer to an inquiry. In Excerpt 2, a REP interviews the leader of a facility (LEF) about the institutional structure, specifically whom LEF can ask for assistance. LEF explains that there are three assisting offices, which REP here formulates as three different lines. She thereupon turns towards the computer. This turn is accomplished in silence. To enable a detailed examination, each dot in Line 05 below represents the tenth of a second:

(2). Rec. 3: 7:49-8:01

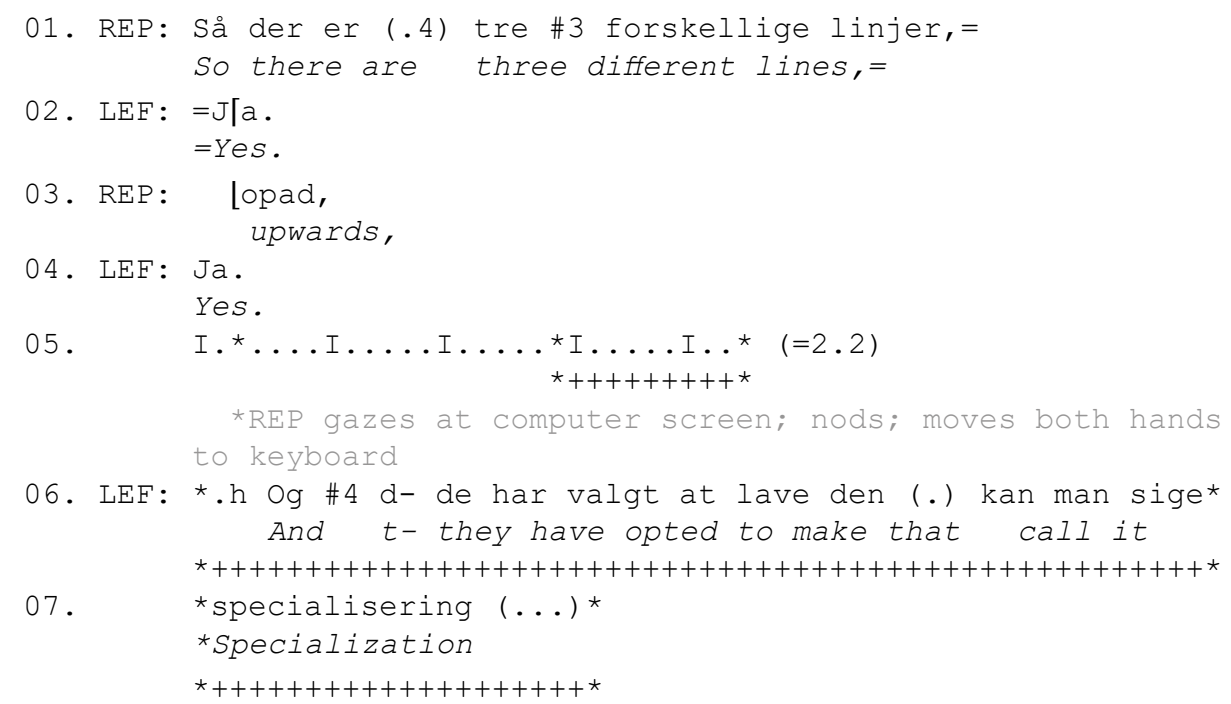

Following LEF's confirmation in Line 04, REP defers from further inquiry to pursue writing instead. This is an orientation towards a different kind of structure than the one in Excerpt 1, that is, where representatives note answers after they have been exhaustively delivered. The orientation is enhanced by the fact that she nods as she gazes at the screen before she actually types. The silent writing, though, turns out to last for merely 0.7 seconds or so, because LEF, in Line 06 ,
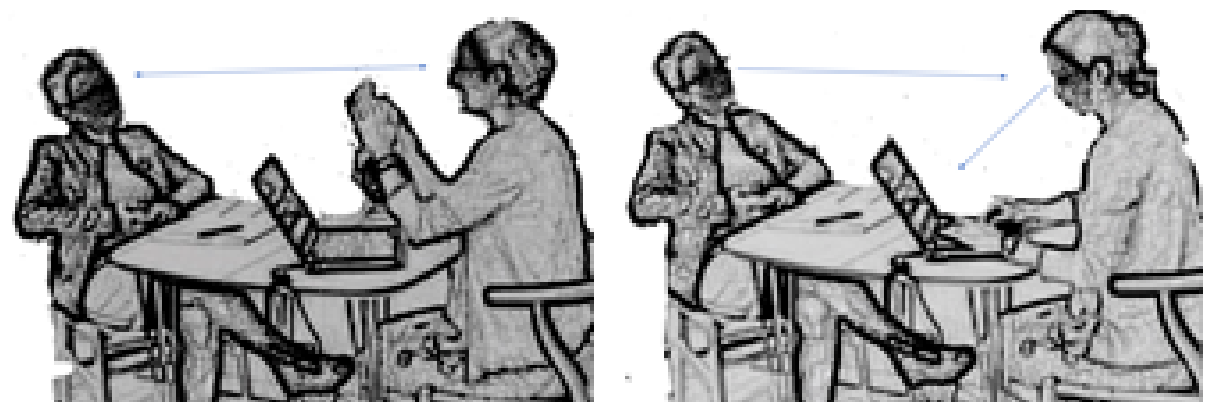
initiates a lengthy explanation. In doing this, LEF treats REP's act of writing as an occasion to relevantly take the floor and convey an explanation that elaborates her prior answer, which possibly provides the representative more details to add to her notes.

This section's examples have illustrated two recurrent ways in which talk and typing are oriented to as concurrent courses of action, thus, treating the dual commitments as interactionally achievable. In particular, the representatives convey that they are capable of writing whilst listening when they overtly prepare to take notes as the foster parents or facility leaders are about to produce answers to inquiries. Conversely, the foster parents and facility leaders convey confidence that the representatives can receive their talk when they, for example, provide unsolicited explanations while the representatives write in silence. To paraphrase Ruusuvuori (2001), typing does not necessarily mean not listening. Nonetheless, the representatives actively display listening. The next section looks at how coparticipants respond to one of the ways in which they do this. With this focus, the analysis moves from onsets of concurrent talk and note-taking in the direction of ongoing reconfigurations that maintain the mutual relevance of the dual activities.

\section{Display of Listening while Taking Notes}

Representatives quite commonly use resources such as minimal tokens, nods, and facial expressions to assure foster parents and facility leaders that they appreciate their talk whilst taking notes. These resources may be used in conjunction with each other forming gestalts, that is, organized and perceived wholes. This section, however, concentrates mainly on some uses of minimal expressions that express recipiency and demonstrably affect foster parents' or facility leaders' talk.

Minimal tokens are notoriously flexible in terms of semantics. A token is, to a large extent, ascribed meaning based upon its sequential placement and prosodic features (see Gardner, 2001, p. 22). That said, previous research has established that particular tokens tend to be used for particular purposes, for example, to convey the recipient's cognitive change of state (Heinemann, 2017), encourage continuation (Schegloff, 1982), or acknowledge reception (Gardner, 2001). The following example may serve as an illustration of how minimal tokens are produced to administer expeditious changes, which dual participation in interaction and writing often involves. A REP invokes the token "ja" ("yes") to encourage a LEF to complete her turn at talk. Prior to the excerpt, she has asked LEF if she is personally enrolled in a supervision program, which the social supervision center strongly recommends. LEF is not. However, she explains that a particular co-worker provides her good counselling. Line 01 in Except 3 is the main consequent clause of a conditional sentence that outlines what happens when the leader approaches this co-worker for advice. REP's hands are placed on the computer's keyboard at the onset of Line 01, yet it is not until mid-turn that 
REP actually begins to type:

(3). Rec. 3: 47:34-47:44

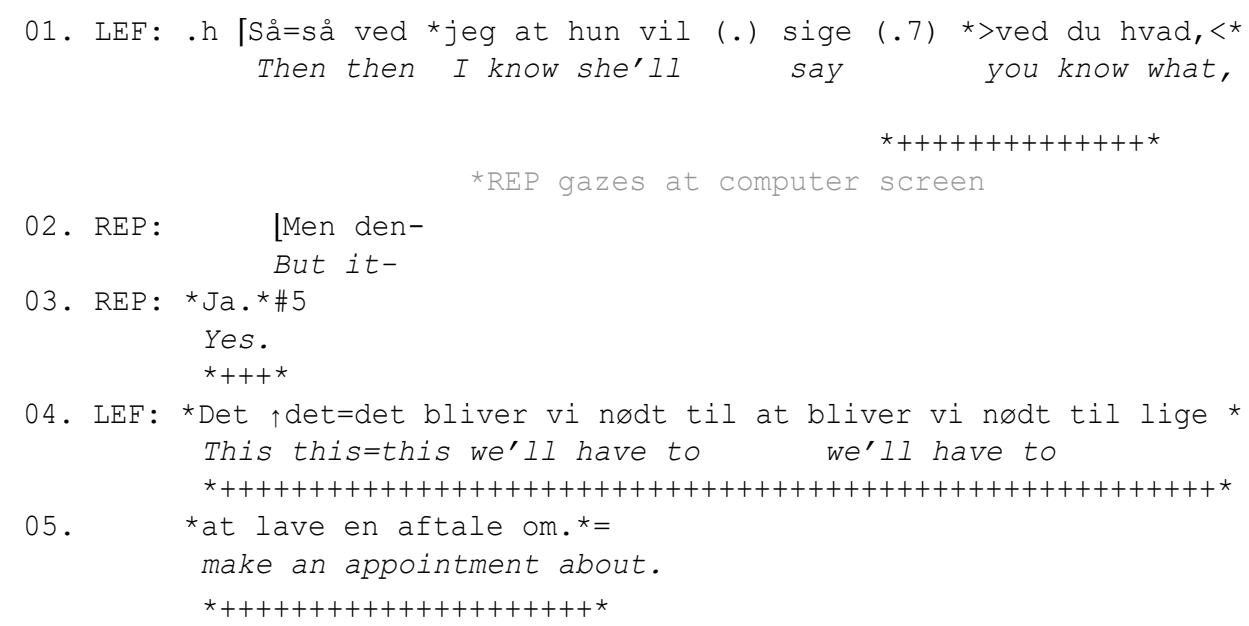

In Line 02, REP initiates a turn at talk in overlap with LEF, but quickly cutsoff and yields the floor to the leader (see Schegloff, 2000). Immediately after the cut-off, REP gazes down at her computer. Seconds later she begins to write. Thus, this writing sequence is implemented as an alternative to a verbal contribution, which REP abandons, exploiting the projected status as a listener instead of a

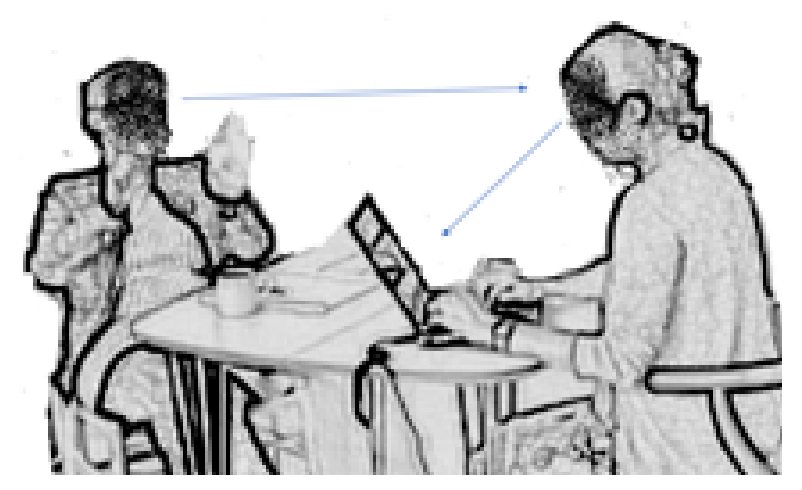

speaker as an opportunity to begin taking notes. Thus, in this light, REP's "yes" token in Line 03 produced in conjunction with note-taking both displays listening whilst typing and ratifies that LEF has the floor.

Taking an even closer look at the positioning of REP's "yes" in Line 03, we may notice that it follows the initial element in the leader's direct reported speech, that is, the preliminary "you know what" clause, whereupon LEF pauses. In other words, LEF treats REP's display of recipiency as a precondition to complete 
the turn at talk. This observation is in line with previous findings that speakers may express hesitance to complete their talk without the ratification attributed to participants' mutual gaze (see Goodwin, 1979, 1980; Ruusuvuori, 2001). By uttering "yes," REP accommodates. In sum, Excerpt 3 offers a detailed illustration of how minimal tokens may be used to establish joint attention towards the talk even though representatives gaze at their computers to take notes at the same time.

Excerpt 4 shows how a facility leader similarly treats a representative's "mm hm" token, produced while typing, as an encouragement to produce further talk. But whereas a minimal token in Excerpt 3 was solicited in order to receive encouragement to complete a turn at talk, Excerpt 4 shows how a facility leader awaits a display of recipiency in order to elaborate with a turn at talk that answers more than the initial question. At this point in the meeting, the parties discuss a master study program, which the leader is currently enrolled in. He has, prior to the example, explained that his study is organized in calls. Here, the representative asks for how long these calls last:

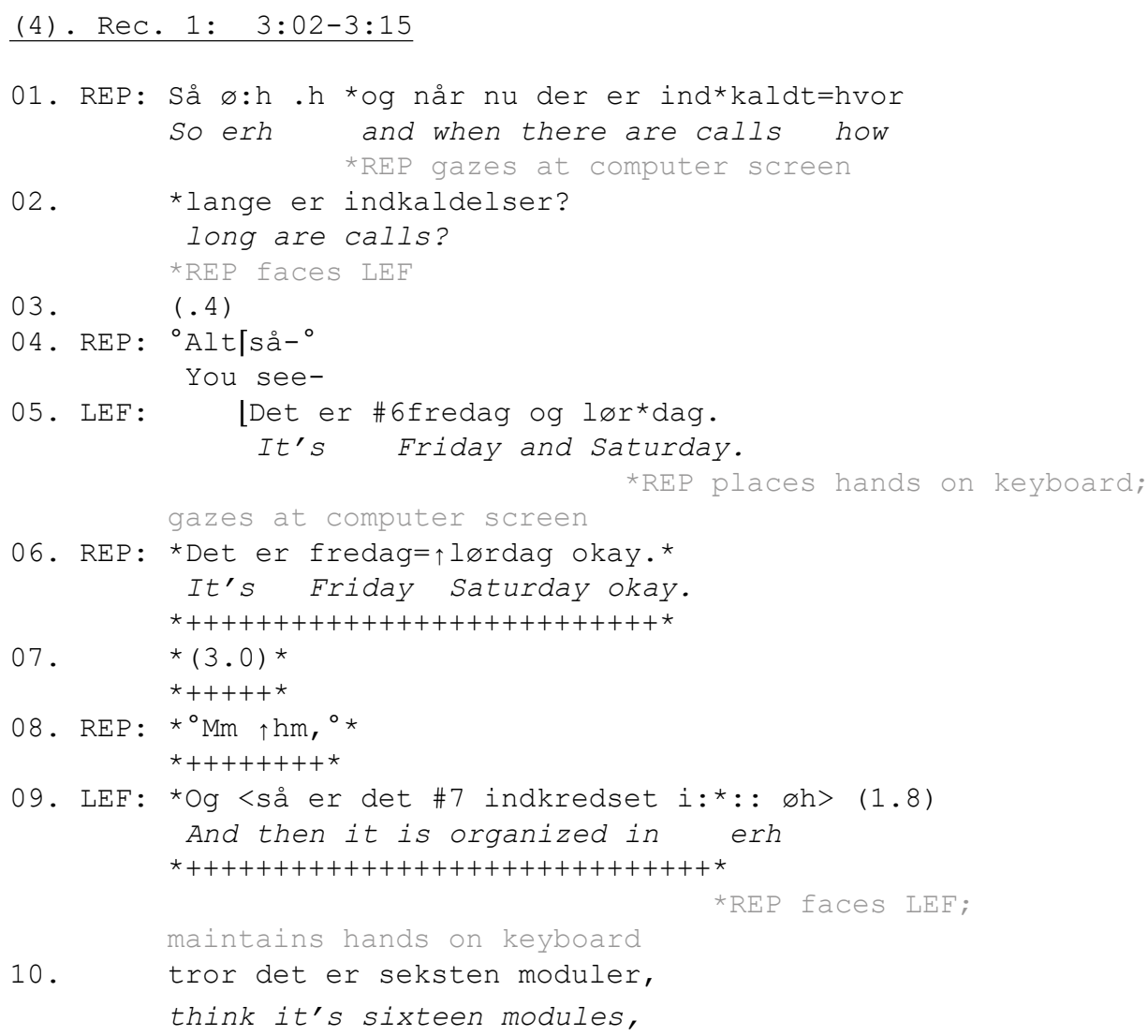

10. tror det er seksten moduler, think it's sixteen modules, 
REP bodily prepares to type as LEF is about to complete his answer (Line $05)$, and REP begins to type in Line 06 in coincidence with a repetition and acknowledgement of that answer. After a three-second-long period in which REP types in silence, she quietly utters a freestanding "mm hm" whilst still typing. LEF observes REP during this stretch of silent typing. He begins his turn-attalk in Line 09 in the very slipstream of the minimal token and produces an elaboration that adds additional and unsolicited information about his study
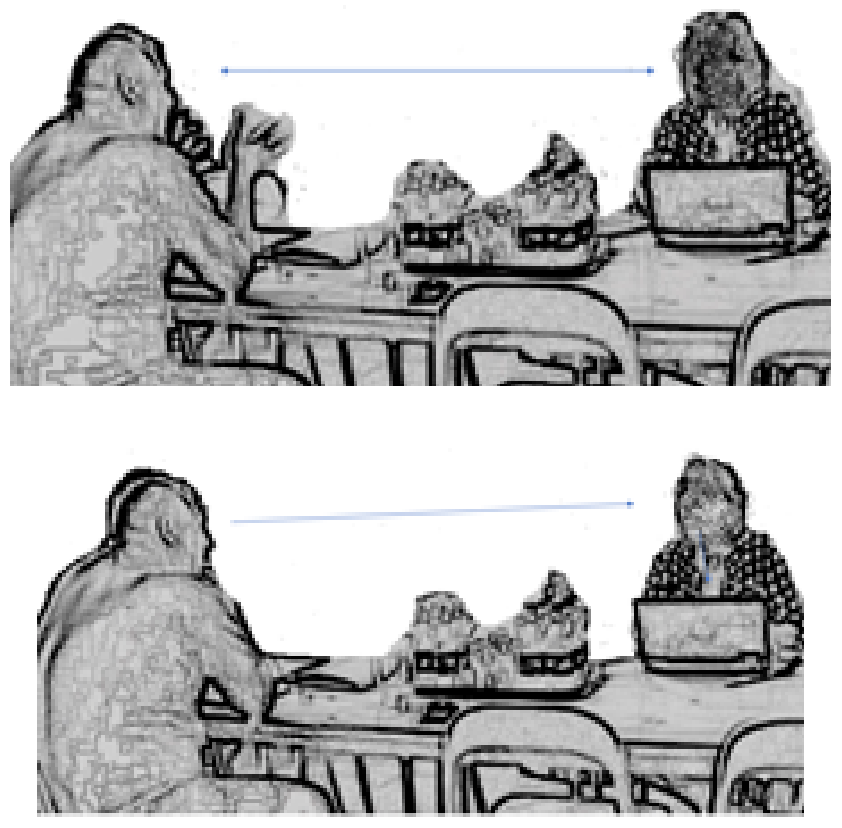

program. This interactional move reflects Stivers and Heritage's (2001) finding that during the history-taking phases of consultations, patients may sometimes expand their answers with more information than the question solicited. But in contrast to Stivers and Heritage's examples, LEF acted as if awaiting REP's signal (i.e., "mm hm") to proceed with an expansion.

As mentioned, one of the main characteristics of minimal tokens is their low degree of semantic content. This feature manifests itself here where it is impossible for the analysts and participants (i.e., LEF) alike to determine what exactly REP's "mm hm" expression orients towards. Is it, for example, produced socially to convey that LEF is welcome to resume his talk? Or is it produced more privately, that is, as a sort of self-talk, possibly to express having completed the notation of LEF's previous answer? Or could it be a combination of the two? A recent multiactivity study from a very different setting involving mucking out a sheep stable suggests that volume, gaze direction, and body posture may determine how co-participants understand minimal comments as either social or self-talk (Keevallik, 2018). But in this case, where REP remains seated, keeps her 
torso stable (Schegloff, 1998), and continues to write and gaze at the computer screen, there seems to be no distinct bodily actions that index the expression's meaning. However, we can positively observe two things. First, regardless of ambiguity, LEF treats REP's expression as an occasion to talk again, which, in turn, prompts REP in Line 09 to momentarily pause the act of writing to engage with LEF displaying full attention (more examples of this practice are analyzed in detail in the section below). Second, LEF initiates his turn with an "and"conjunction that ties the current turn at talk to his own previous contribution in Line 05 , distinctively making it an elaboration of his answer. Thus, REP's use of a minimal token while writing allows the participants to jointly reconfigure the interaction and LEF to overtly resume and expand his explanation.

In sum, the above excepts showed how the representatives verbally display listening while they make notes, and how the foster parents and facility leaders may respond to representatives' minimal tokens as encouraging continuation. The next section looks at how the representatives can display listening by the means of brief suspensions of typing.

\section{Display of Listening Between Taking Notes}

Erving Goffman (1963) was one of the first observers of the ways in which interactants preserve mutual involvements. He was also an observer of how talk and interaction often tend to be organized in very focused spurts (e.g., Goffman, 1967, p. 37). The current section shows that Goffman's two observations are not mutually exclusive. Table 1 above showed the overall distribution of the representatives' writing activity. It illustrates that many writing sequences are kept very short - produced as spurts - because the representatives suspend the act of writing to frequently and briefly to engage with their co-participants. These engagements can be coordinated actions, made relevant by the speakers' contributions, and treated as displays of listening, which encourages speakers to continue.

Excerpt 5 offers an illustration. The participants discuss the facility's values and core tasks. Here, LEF confirms REP's preceding assertion that strategies should be resident-centered. She elaborates:

(5). Rec. 3. 35:22-35:39

01. LEF:.h Ja fordi man kan sige *når vi arbejder *her

Yes because you could say when we work here

02. og arbejder [med det vi gør så er *vor m- vores missi*on* and work with what we do then our $m^{-}$our mission 


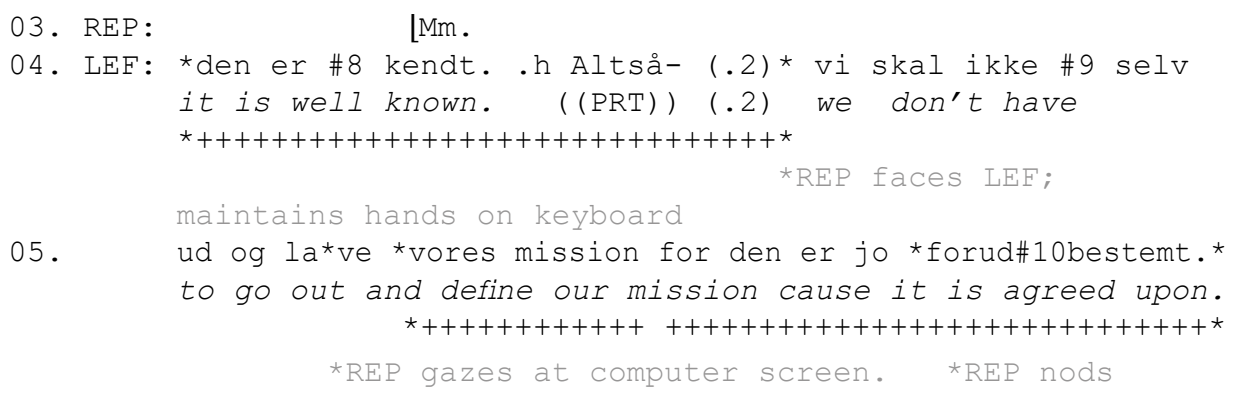

Unlike the use of minimal tokens, which the previous section analyzed, and REP's nod in Line 05 aside, a noteworthy difference is that the display of listening is conveyed not during but between the acts of writing. That is, in Lines 04-05, REP briefly suspends the act of writing to face the facility leader.

REP begins to take notes on her computer as LEF, currently in a mid-turn position, produces what turns out to be a lengthy explanation, that is, a multiunit turn at talk. Specifically, the actual typing is prepared with a quick glance at the computer screen (see Beck Nielsen, 2019) alongside a subordinate clause
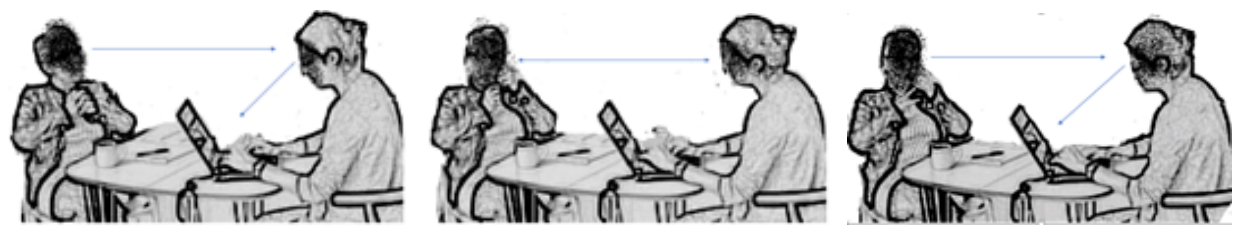

produced by LEF and instantiated in conjunction with the following main clause. LEF maintains gaze on REP throughout this and conveys no verbal or bodily sign of being troubled by the fact that REP directs her gaze at computer screen whilst LEF is in the midst of a turn at talk (in contrast to Ruusuvuori's, 2001, findings). However, in Line 04, LEF reaches a possible completion point and self-selects to continue (cf. Sacks et al., 1974). She does so with a turn-initial "altså" - a particle that is known to justify a departure from progressivity, for example by projecting relevant corrections or expansions (see Heinemann \& Steensig, 2018). Here, this turn-initial particle could perhaps project that LEF's forthcoming and somewhat repetitive assertion that the facility's mission is well-established and familiar might be construed as a departure from progressivity in the service of being very accurate. But a closer look shows a more immediate interactional function, still oriented towards a departure from progressivity of sorts.

LEF cuts off "altså" with a glottal stop followed by a brief pause. That is, LEF suspends her explanation. This suspension, in turn, prompts REP to suspend her writing and briefly face LEF. Interactionally, glottal stops are known for their turn-holding functions (e.g., Ogden 2001). In this particular case, LEF indeed holds the turn, exactly until she has ensured the visual attention of REP 
(similar to dynamics originally elucidated by Goodwin, 1979, 1980, 1981). This mutual gaze and suspension of writing is short but consequential - as many other studies have revealed that momentary mutual gaze may be (e.g., Rossano, 2012; Streeck, 2014). Its momentariness is enacted by REP maintaining her hands on the keyboard, quite similar to the instability displayed when actors working on computers torque their torso to momentarily engage with other participants (Schegloff, 1998). This momentariness is also confirmed as REP briefly gazes back at the computer screen and begins to write. But at this point, LEF is well into the continuation of what is now a multi-unit turn - made relevant by REP's brief writing suspension in favor of engagement.

This section has demonstrated the seemingly counterintuitive observation that a way to ensure the integration of talk and note-taking is to have the notetaking suspended for a brief period of time in favor of mutual gaze. This a reminder that gaze direction is an accountable matter that interlocutors take as a sign of orientation, which the sociologist Georg Simmel described eloquently: "the eye cannot take unless at the same time it gives" (1924, p. 358).

\section{Concluding Remarks}

Rather than treating the dual administration of participation in talk in interaction and note-taking as a question of cognitive capacity, the current study has looked into some ways in which participants engaged in institutional monitoring visits integrate the two courses of action interactionally. The representatives spend an overall average of $17 \%$ of the time taking notes on their computers during the meetings. A closer conversation analytic examination of the data revealed that the two courses of action regularly coincide because both parties orient towards them as mutually possible. This stands in contrast to, for instance, David Greatbatch's (2006) finding about general practitioners' use of computers to write prescriptions during consultation. He noted that patients "usually minimize the likelihood that they will disrupt the doctors' computerbased activities by delaying their questions until potential junctures in the doctor's use of the computer" (2006, p. 330). Conversely, Excerpt 2 showed that speakers recurrently make simultaneous talk relevant by taking the floor in situations where representatives begin to write in silence, for example, to elaborate a prior comment or response. Similarly, Excerpt 1 showed that writers convey that it is equally possible and appropriate for them to take notes while they listen to talk when they commence writing sequences in coincidence with either the onset or a midturn position of foster parents' or facility leaders' answers to their inquiries.

However, integration of talk and note-taking is more than a matter of coordinated onsets. It may require continuous reconfiguration. The current study found that some reconfigurations take place while representatives write using minimal tokens, among other verbal and bodily resources. Excerpts 3 and 4 
illustrated that representatives convey listening by the means of such minimal tokens and that the speakers are especially prone to treat the representatives' minimal tokens as continuers when produced while the representatives write, as opposed to, for instance, acknowledgement tokens or self-talk. The current study also found that other reconfigurations take place between the act of writing, in the sense that the representatives frequently display attentiveness to the coparticipants' talk by briefly suspending the note-taking to face the speakers. Excerpt 5 illustrated the participants' joint orientation towards the use of this embodied way of displaying attention and, thereby, reconfiguring the interaction into a situation where the dual activities talk and note-taking may relevantly concur because the speaker is ensured that the writer still pays attention to the talk. 


\section{Appendix: Transcription Symbols}

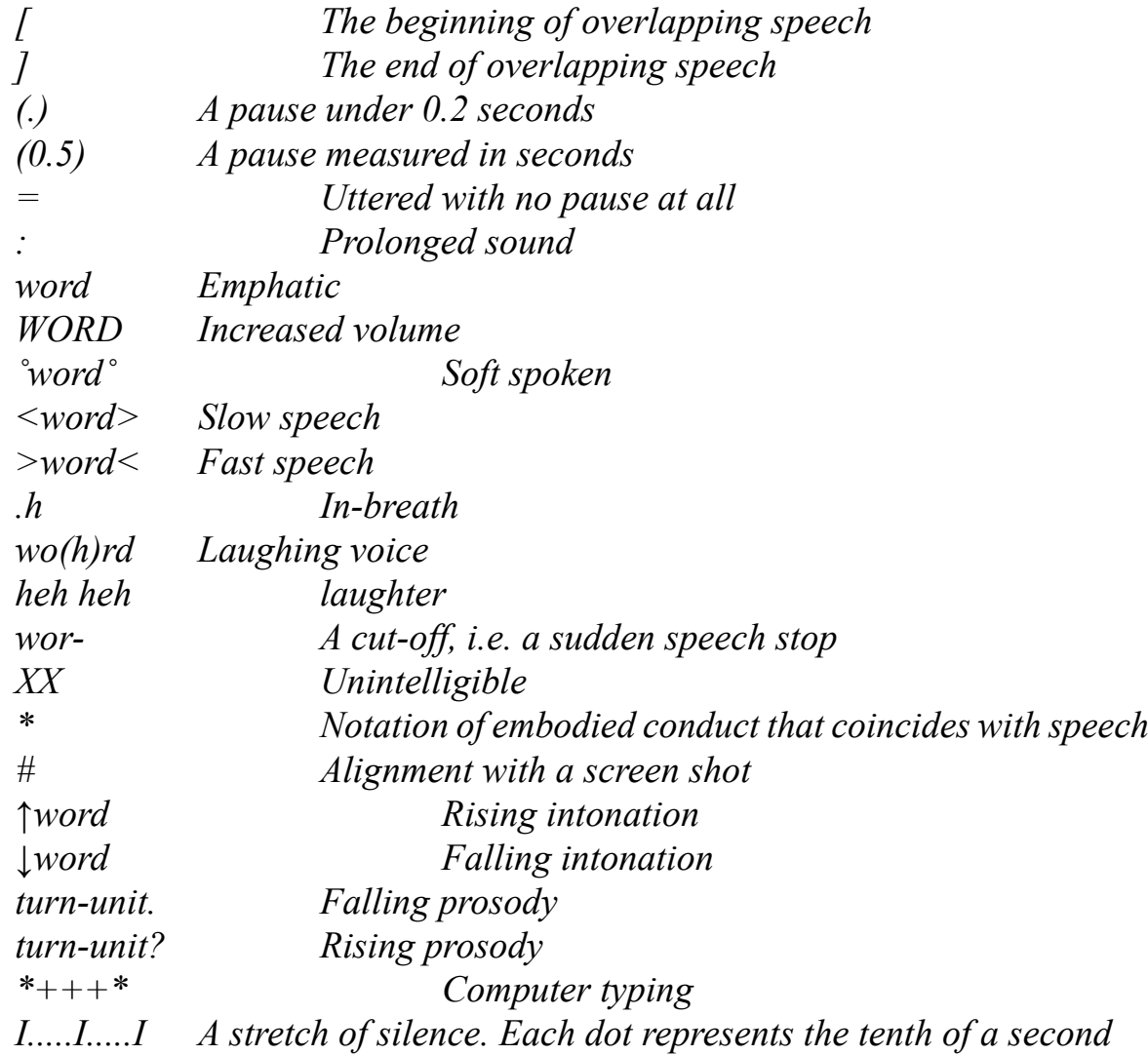


INTERACTIONAL INTEGRATION OF TALK AND NOTE-TALKING 162

\section{Acknowledgments}

The author is highly grateful for the two anonymous reviewers' constructive criticism as well as for the assistance and support of the editorial team.

\section{Conflict of Interest Disclosure}

The author declares no conflicts of interest.

\section{Funding}

The research was conducted without external funding.

\section{Research Ethics Statement}

The research was conducted in accordance with appropriate ethical standards, please see specifics in the Data and Method section. 


\section{References}

Beck Nielsen, S. (2014). Medical record keeping as an interactional accomplishment. Pragmatics and Society, 5(2), 221-242. httpss://doi. org/10.1075/ps.5.2.03nie.

Beck Nielsen, S. (2016). How doctors manage consulting computer records while interacting with patients. Research on Language and Social Interaction, 49(1), 58-74. httpss://doi.org/10.1080/08351813.2016.1126451

Beck Nielsen, S. (2019). Making a glance an action: Doctors' quick looks at their destop computer screens. Journal of Pragmatics, 142, 62-74. httpss://doi. org/10.1016/j.pragma.2018.12.021

Bowman, L. L., Levine, L. E., Waite, B. M., \& Gendron, M. (2010). Can students really multitask? An experimental study of instant messaging while reading. Computers \& Education, 54(4), 927-931. httpss://doi.org/10.1016/j. compedu.2009.09.024

Clift, R. (2016). Conversation analysis. Cambridge Textbooks in Linguistics.

Cowley, S. (2012). Mimesis and language: A distributed view. Interaction Studies, 13(1), 17-40. httpss://doi.org/10.1075/is.13.1.02cow

Duncan, J. (1979). Divided attention: The whole is more than the sum of its parts. Journal of Experimental Psychology: Human Perception and Performance, 5(2), 216-228. httpss://doi.org/10.1037/0096-1523.5.2.216

Ewolds, H., Broeker, L., de Oliveira, R. F., Raab, M., \& Künzell, S. (2021). Ways to improve multitasking: Effects of predictability after single- and dual-task training. Journal of Cognition, 4(1), 4. https://doi.org/10.5334/joc. 142

Fox, B. A. \& Thompson, S. A. (2010). Responses to wh-questions in English conversation. Research on Language and Social Interaction, 43(2), 133156. httpss://doi.org/10.1080/08351811003751680

Gardner, R. (2001). When listeners talk. Response tokens and listener stance. John Benjamins. httpss://doi.org/10.1075/pbns.92

Goffman, E. (1963). Behavior in public places. Notes on the social organization of gatherings. The Free Press.

Goffman, E. (1967). Interaction ritual. Essays on face-to-face behavior. Pantheon Books. González Martínez, E. (2006). The interweaving of talk and text in a French criminal pretrial hearing. Research on Language and Social Interaction, 39(3), 229-261. https://dx.doi.org/10.1207/s15327973rlsi3903_3

Goodwin, C. (1979). The interactive construction of a sentence in natural conversation. In G. Psathas (Ed.), Everyday language: Studies in ethnomethodology (pp. 97-121.). Irvington Publishers.

Goodwin, C. (1980). Restarts, pauses, and the achievement of mutual gaze at turn-beginning. Sociological Inquiry, 50(3-4), 272-302.

Goodwin, C. (1981). Conversational organization: Interaction between speakers and hearers. Academic Press.

Greatbatch, D. (2006). Prescriptions and prescribing: Co-ordinating talk and 
text-based activities. In J. Heritage \& D. W. Maynard (Eds.), Communication in medical care: Interaction between primary care physicians and patients (pp. 313-339). Cambridge University Press.

Haddington, P. (2019). Leave-taking as multiactivity: Coordinating conversational closings with driving in cars. Language \& Communication, 65, 58-78. httpss://doi.org/10.1016/j.langcom.2018.04.003

Haddington, P., Keisanen, T., Mondada, L., \& Nevile, M. (Eds.). (2014). Multiactivity in social interaction: beyond multitasking. John Benjamins.

Halldorsdottir, I. (2006). Orientations to law, guidelines, and codes in lawyerclient interaction. Research on Language and Social Interaction, 39(3), 263301. https://dx.doi.org/10.1207/s15327973rlsi3903_4

Hazel, P. \& Mortensen, K. (2014). Embodying the institution - Object manipulation in developing interaction in study counselling meetings. Journal of Pragmatics, 65, 10-29. https://dx.doi.org/10.1016/j.pragma.2013.11.016 Heinemann, T. (2017). Receipting answers that are counter to expectations: The polar question-answer-nå sequence in Danish. Research on Language and Social Interaction, 50(3), 249-267, https://dx.doi.org/10.1080/08351813

Heinemann, T., \& Steensig, J. (2018). Justifying departures from progressivity: The Danish turn-initial particle 'altså'. In J. Heritage \& M. L. Sorjonen (Eds.), In between turn and sequence: Turn-initial particles across languages (pp. 445476). John Benjamins httpss://doi.org/10.1075/slsi.31.15hei.2017.1340705

Heinemann, T., \& Rauniomaa, M. (2016). Turning down sound to turn to talk: Muting and muffling auditory objects as a resource for displaying involvement. Gesprächsforschung - Online-Zeitschrift zur verbalen Interaktion, 17, 1-28. https:/www.gespraechsforschung-online.de/fileadmin/dateien/heft2016/gaheinemann.pdf

Jefferson, G. (2004). Glossary of transcript symbols with an introduction. In G. Lerner (Ed.), Conversation analysis. Studies from the first generation (pp. 13-31). John Benjamins. httpss://doi.org/10.1075/pbns.125.02jef

Jensen, T. W. (2014). Emotion in languaging: Languaging as affective, adaptive, and flexible behavior in social interaction. Frontiers in Psychology, 5:720. httpss://doi.org/10.3389/fpsyg.2014.00720

Jensen, T. W. (2018). Humor as interactional affordances: An ecological perspective on humor in social interaction. Psychology of Language and Communication, 22, 238-259. httpss://doi.org/10.2478/plc-2018-0010

Keevallik, L. (2018). Sequence initiation or self-talk? Commenting on the surroundings while mucking out a sheep stable. Research on Language and Social Interaction, 51(3), 313-328. httpss://doi.org/10.1080/08351813.2018.1485233

Kiesel, A., Steinhauser, M., Wendt, M., Falkenstein, M., Jost, K., Philipp, A. M., \& Koch, I. (2010). Control and interference in task switching-A review. Psychological Bulletin, 136(5), 849-874. httpss://doi.org/10.1037/a0019842 Komter, M.L. (2006). From talk to text: The interactional construction of a police record. Research on Language and Social Interaction, 39(3), 201-228. 
httpss://doi.org/10.1207/s15327973rlsi3903_2

Komter, M. L. (2012). The career of a suspect's statement: Talk, text, context. Discourse Studies, 14(6), 731-752. httpss://doi. org/10.1177/1461445612457486

Laurier, E. (2008). Drinking up endings: Conversational resources of the café. Language \& Communication, 28(2), 165-181. httpss://doi.org/10.1016/j. langcom.2008.01.011

Licoppe, C. \& Tuncer, S. (2014). Attending to a summons and putting other activities 'on hold'. In P. Haddington, T. Keisanen, L. Mondada, \& M. Nevile (Eds.), Multiactivity in social interaction: Beyond multitasking (pp. 167-190). John Benjamins.

Meiran, N. (1996). Reconfiguration of processing mode prior to task performance. Journal of Experimental Psychology: Learning, Memory, and Cognition, 22(6), 1423-1442. httpss://doi.org/10.1037/0278-7393.22.6.1423

Mondada, L. (2009). The methodical organization of talking and eating: Assessments in dinner conversations. Food Quality and Preference, 20(8), 558-571. httpss://doi.org/10.1016/j.foodqual.2009.03.006

Mondada, L. (2012). Talking and driving. Multiactivity in the car. Semiotica, 191(1/4), 223-256. httpss://doi.org/10.1515/sem-2012-0062

Mondada, L. (2014). The temporal orders of multiactivity: Operating and demonstrating in the surgical theatre. In P. Haddington, T. Keisanen, L. Mondada \& M. Nevile (Eds.), Multiactivity in social interaction: Beyond multitasking (pp. 33-76). John Benjamins.

Mondada, L. (2016). Going to write. Embodied trajectories of writing of collective proposals in grassroots democracy meetings. Language and Dialogue, 6(1), 140-178. httpss://doi.org/10.1075/ld.6.1.05mon

Mondada, L. (2017). Walking and talking together: Questions/answers and mobile participation in guided visits. Social Science Information, 56(2), 220-253. httpss://doi.org/10.1177/0539018417694777

Mondada, M., \& Svinhufvud, K. (2016). Writing-in-interaction. Studying writing as a multimodal phenomenon in social interaction. Language and Dialogue, 6(1), 1-53. httpss://doi.org/10.1075/1d.6.1.01mon

Monteiro, D. (2016). Street-level bureaucracy revisited. Formulating address in social work service encounters. Language and Dialogue, 6(1), 54-80. httpss://doi.org/10.1075/ld.6.1.02mon

Nishizaka, A., \& Sunaga, M. (2015). Conversing while massaging: Multidimensional asymmetries of multiple activities in interaction. Research on Language and Social Interaction, 48(2), 200-229. httpss://doi.org/10.10 $80 / 08351813.2015 .1025506$

Ogden, R. (2001). Turn transition, creak and glottal stop in Finnish talk-ininteraction. Journal of the International Phonetics Association, 31, 139-152. httpss://doi.org/10.1017/S0025100301001116

Pashler, H. (1984). Processing stages in overlapping tasks: Evidence for a central 
bottleneck. Journal of Experimental Psychology: Human Perception and Performance, 10(3), 358-377. httpss://doi.org/10.1037/0096-1523.10.3.358

Rossano, F. (2012). Gaze in conversation. In J. Sidnell \& T. Stivers (Eds.), The handbook of conversation analysis (pp. 308-329). Wiley Blackwell.

Rogers, R. D. \& Monsell, S. (1995). Costs of a predictible switch between simple cognitive tasks. Journal of Experimental Psychology: General, 124(2), 207231. httpss://doi.org/10.1037/0096-3445.124.2.207

Ruusuvuori, J. (2001). Looking means listening: Coordinating displays of engagement in doctor-patient interaction. Social Science and Medicine, 52(7), 1093-1108. httpss://doi.org/10.1016/S0277-9536(00)00227-6

Sacks, H., Schegloff, E. A. \& Jefferson, G. (1974). A simplest systematics for the organization of turn-taking for conversation. Language, 50(4), 969-735. httpss://doi.org/10.2307/412243

Sidnell, J. (2010). Conversation analysis: An introduction. Wiley Blackwell Simmel, G. (1924). Sociology of the senses: Visual interaction. In R. E. Park, \& E. W. Burges (Eds.), Introduction to the science of sociology (pp. 356-361). University of Chicago Press

Schegloff, E. A. (1982). Discourse as an interactional achievement: Some uses of 'uh huh' and other things that come between sentences. In D. Tannen (Ed.), Analyzing discourse: Text and talk (pp. 71-93). Georgetown University Press. Schegloff, E. A. (1998). Body torque. Social Research, 65(3), 535-596.

Schegloff, E. A. (2000). Overlapping talk and the organization of turn-taking for conversation. Language in Society, 29(1), 1-63.

Stivers, T. \& Heritage, J. (2001). Breaking the sequential mold: Answering 'more than the question' during comprehensive history taking. Text \& Talk, 21(1-2), 151-185 Streeck, J. (2014). Mutual gaze and recognition: Revisiting Kendon's 'Gaze direction in two-person conversation'. In M. Seyfeddinipur \& M. Gullberg (Eds.), From gesture in conversation to visible action as utterance: Essays in honor of Adam Kendon (pp. 35-56). John Benjamins.

Streeck, J., \& Kallmeyer, W. (2001). Interaction by inscription. Journal of Pragmatics, 33(4), 465-490. httpss://doi.org/10.1016/S0378-2166(99)00126-5

Svinhufvud, K. (2016). Nodding and note-taking. Multimodal analysis of writing and nodding in student counseling interaction. Language and Dialogue, 6(1), 81-109. httpss://doi.org/10.1075/ld.6.1.03svi

Svinhufvud, K., \& Vehviläinen, S. (2013). Papers, documents, and the opening of an academic supervision encounter. Text \& Talk, 33(1), 139-166. httpss:// doi.org/10.1515/text-2013-0007

Ticca, A. C. (2014). Managing multiactivity in a travel agency: Making phone calls while interacting with costumers. In P. Haddington, T. Keisanen, L. Mondada, \& M. Nevile (Eds.), Multiactivity in social interaction: Beyond multitasking (pp. 191-223). John Benjamins.

Trasmundi, S. B. (2020). Errors and interaction: A cognitive ethnography of emergency medicine. John Benjamins. httpss://doi.org/10.1075/pbns.309 
Trasmundi, S. B., \& Steffensen, S. V. (2016). Meaning emergence in the ecology of dialogical systems. Psychology of Language and Communication, 20(2), 154-181. httpss://doi.org/10.1515/plc-2016-0009

Wechsler, K., Drescher, U., Janouch, C., Haeger, M., Voelcker-Rehage, C. \& Bock, O. (2018). Multitasking during simulated car driving: A comparison of young and older persons. Frontiers in Psychology, 9:910. httpss://doi. org/10.3389/fpsyg. 2018.00910 